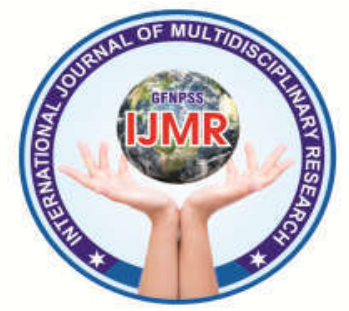

\title{
PREVALENCE OF DENTAL PULP STONES IN CORONARY ARTERY DISEASE PATIENTS - A DIGITAL ORTHOPANTOMOGRAPHIC STUDY
}

\author{
Dr. BHAVNA BARTHUNIA ${ }^{1}$, Dr. POULOMI BHAKTA ${ }^{2}$ \\ ${ }^{1}$ PROF. \& HOD, DEPT. OF ORAL MEDICINE \& RADIOLOGY, DASWANI DENTAL \\ COLLEGE \& RESEARCH CENTRE,RANPUR, KOTA, RAJASTHAN, INDIA \\ ${ }^{2}$ SENIOR LECTURER, DEPT. OF ORAL MEDICINE \& RADIOLOGY, DASWANI \\ DENTAL COLLEGE \& RESEARCH CENTRE,RANPUR, KOTA, RAJASTHAN, INDIA \\ Corresponding Email: poulomibhakta@gmail.com
}

\section{ABSTRACT}

Background and objective: Coronary artery disease is the most common form of cardiovascular disease. Calcifying nanoparticles, are the first calcium phosphate mineral containing particles isolated from human blood and were detected in numerous pathologic calcification related process such as atherosclerosis, renal lithiasis and dental pulp stone formation. Coronary artery diseases are more frequently associated with dental pulp stones.

Methods: The total number of subjects for the study was 100 with an age range of $20-$ $60 y$ rs.Group I comprised of 50 healthy subjects as controls. Group II comprised of 50 subjects who were diagnosed patients of coronary artery disease. They were then subjected to orthopantomograph. The prevalence of pulp stones and the statistical significance was assessed using chi-square test and t test.

Results: The number of subjects with presence of dental pulp stones in group I (controls) was $28 \%$ and group II (CAD cases) was $86 \%$. The observed values were statistically significant $(\mathrm{P}<0.001)$. The mean no. of subjects with dental pulp stones was found to be more in group II when compared with group I and the observed difference was found to be statistically significant $(\mathrm{P}<0.001)$. The number of teeth with pulp stones was found to be higher in group II than group I.

Interpretation and conclusion: There is a possible association of dental pulp stones with coronary artery disease. Hence, dental professionals play a pivotal role in detection of dental pulp stones and referral of patients to the cardiologist for appropriate investigations and management of coronary artery disease.

Keywords: Coronary artery disease, Dental pulp stones, Orthopantomographs. 


\section{INTRODUCTION}

Coronary artery disease is a multifactorial condition, resulting from the convergence of genetics, environment, diet, and lifestyle. ${ }^{1}$ The incidence of coronary artery disease has doubled during past three to four decades. It will soon emerge as the single largest disease accounting for nearly one-third of all deaths in India. ${ }^{2}$ The contributing factors or the growing burden of cardiovascular diseases (CVDs) are increasing prevalence of cardiovascular risk factors especially hypertension, dyslipidemia, diabetes, overweight or obesity, physical inactivity and tobacco use. ${ }^{3}$

Atherosclerosis, is thought to be a chronic inflammatory process of the arterial wall induced, at least in part, by endogenous toxic plasma lipid components. It is a common phenomenon which is seen with different prevalence in different races. The clinical expressions of atherosclerosis may be chronic, as in the development of stable, effort-induced angina pectoris or of predictable and reproducible intermittent claudication. Alternatively, a much more dramatic acute clinical event such as infarction, a cerebrovascular accident, or sudden cardiac death may first herald the presence of atherosclerosis. ${ }^{4}$

Calcifying nanoparticles (CNP) play a very crucial role in numerous pathologic calcification related diseases, as in atherosclerosis, dental pulp stones, salivary gland stones, black pigment gall stones, arterial calcification, heart diseases (local calciphylaxis on the mitral valve and calcific aortic valve stenosis), periodontal diseases (gingivitis and periodonitis); and are the first calcium phosphate mineral containing particles isolated from human blood. $^{5}$

Coronary artery diseases are more frequently associated with dental pulp stones which are discrete or diffuse calcified structures present in any portion of the pulp tissue.They are more common in the pulp chamber of posterior teeth. Pulp stones may exist freely within the pulp tissue or be attached to or embedded in dentine. Kronfield has classified pulp stones into discrete (denticles and pulp nodules) and diffuse types based on the morphology. Seltzer has classified them based on their structure into true and false types; based on size into fine and diffuse mineralization, and based on location into embedded and free types. ${ }^{6}$ 


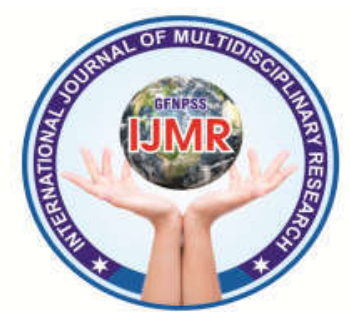

The present study was designed with the following aims \& objectives:

1. To study the presence of dental pulp stones on orthopantomograph in coronary artery disease patients.

2. To study the presence of dental pulp stones on orthopantomograph in controls.

3. To evaluate the prevalence of dental pulp stones in coronary artery disease.

4. To determine the association between dental pulp stones and coronary artery disease.

\section{MATERIALS AND METHODS}

The present study was conducted by selecting subjects with coronary artery disease who visited the Department of Oral Medicine and Radiology at the Daswani Dental College and Research Centre, Kota, Rajasthan.

The total number of subjects for the study was 100 with an age range of $20-60 \mathrm{yrs}$.

They were divided in to 2 groups.

Group I comprised of 50 healthy subjects as controls who were referred for orthopantomograph in the course of their dental treatment.

Group II comprised of 50 subjects who were diagnosed patients of coronary artery disease. The diagnosis was confirmed with the help of angiogram reports and other cardiac function tests.
The controls were age and gender matched.

\section{INCLUSION CRITERIA}

1. Subjects of age between 20 - 60years.

2. Subjects who were diagnosed as patients of coronary artery disease.

3. Subject who were referred to obtain orthopantomograph for dental treatment.

\section{EXCLUSION CRITERIA}

1. Grossly destructed teeth/ extensive restorations/ periodontal pathology

2. Teeth with metallic restoration.

3. Patients who were pregnant.

4. Patients with neuromuscular disease. After informed consent, a detailed case history with thorough medical history was recorded and clinical examination was performed on all the subjects. They were then subjected to orthopantomograph following the radiation protection protocol, using PLANMECA PROLINE $\mathrm{XC}$ digital panoramic and cephalometric system. The parameters used are: $70 \mathrm{kVp}$, $10 \mathrm{~mA}, 18$ seconds.

Determination of pulp stones in controls and cases in this study consisted of examining the orthopantomographs for radiopaque objects in either the pulp chamber or pulp canal. Any distinct radiopaque object, free or attached, identifiable in the pulp chamber or pulp 


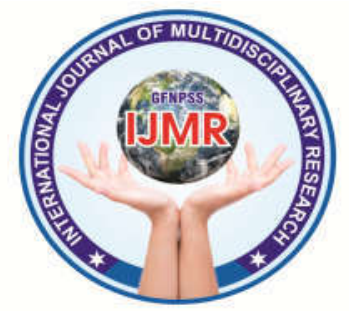

canal of the first and second premolars, and molars were evaluated as a pulp stone.

To ensure the accuracy of the diagnosis, all the radiographs were interpreted by two examiners.

The prevalence of pulp stones in both the groups were assessed. The total number of teeth with pulp stones in a given patient was tabulated. The mean value of all the variables were calculated. Chi-square test and t-test was performed to check for statistical significance.

\section{RESULTS:}

In the current study, a total sample size of 100 subjects, with age ranging from 20 $60 \mathrm{yrs}$ was selected.

The subjects were divided in to 2 groups:

Group I comprised of 50 healthy subjects as controls.

Group II comprised of 50 subjects who were diagnosed cases of coronary artery disease.

The data was collected, tabulated and the results were subjected to statistical analysis where in a chi-square test and a ttest was used.

TABLE 1. NUMBER OF SUBJECTS WITH DENTAL PULP STONES IN GROUP I AND GROUP II: (CHISQUARE TEST)

\begin{tabular}{|c|c|c|c|c|c|c|}
\hline \multirow{2}{*}{ Pulp } & \multicolumn{2}{|c|}{ Group I } & \multicolumn{2}{c|}{ Group II } & \multirow{2}{*}{ (controls) } & \multicolumn{2}{c|}{ (cases) } & \multirow{2}{*}{$\chi^{2}$} & \multirow{2}{*}{ V- } \\
\cline { 2 - 5 } stone & $\mathbf{N}$ & $\%$ & $\mathbf{n}$ & $\mathbf{\%}$ & & \\
\hline Present & 14 & 28 & 43 & 86 & & \\
\hline Absent & 36 & 72 & 7 & 14 & \multirow{2}{*}{34.313} & $<0.001^{*}$ \\
\hline Total & $\mathbf{5 0}$ & $\mathbf{1 0 0}$ & $\mathbf{5 0}$ & $\mathbf{1 0 0}$ & & \\
\hline
\end{tabular}

*denotes significant association

$$
\text { In group I out of } 50 \quad(100 \%)
$$

subjects, 14 (28\%) had dental pulp stones. In group II out of $50(100 \%)$ subjects, 43 $(86 \%)$ had dental pulp stones. Statistically significant association was found between the presence of dental pulp stone and the groups $(\mathrm{P}<0.001)$. Presence of dental pulp stone was found to be higher in group II compared to group I.

\section{TABLE 2. COMPARISON OF MEAN}

NUMBER OF SUBJECTS WITH

DENTAL PULP STONES BETWEEN

GROUP I AND GROUP II: (T-TEST)

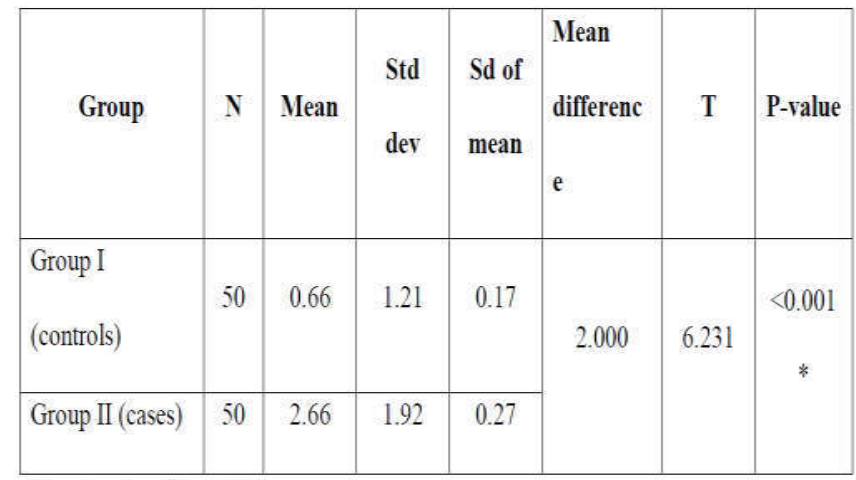

*denotes significant difference 


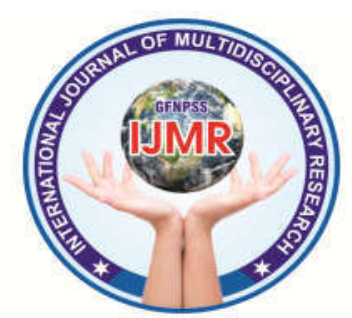

In group I, the mean number of subjects with dental pulp stones was found to be $0.66 \pm 1.21 \mathrm{SD}$. In group II, the mean number of subjects with dental pulp stone was 2.66 \pm 1.92 SD. Mean no. of subjects with dental pulp stones was found to be higher in group II compared to group I and the difference between them was found to be statistically significant $(\mathrm{P}<0.001)$.

TABLE 3.

GROUP I - NUMBER OF TEETH WITH PULP STONES:

\begin{tabular}{|c|c|c|}
\hline Group I & n & $\begin{array}{c}\text { Percentage } \\
(\mathbf{\%})\end{array}$ \\
\hline $\begin{array}{c}\text { Number of teeth with pulp } \\
\text { stones }\end{array}$ & 36 & 5.15 \\
\hline Total number of teeth & 698 & 100 \\
\hline
\end{tabular}

In group I, the total number of teeth evaluated was $698(100 \%)$, out of which $36(5.15 \%)$ teeth had pulp stones.

TABLE 4.

GROUP II - NUMBER OF TEETH WITH PULP STONES:

\begin{tabular}{|c|c|c|}
\hline Group II & $\mathbf{n}$ & $\begin{array}{c}\text { Percentage } \\
(\%)\end{array}$ \\
\hline $\begin{array}{c}\text { Number of teeth with pulp } \\
\text { stones }\end{array}$ & 130 & 20.03 \\
\hline Total number of teeth & 649 & 100 \\
\hline
\end{tabular}

In group II, the total number of teeth evaluated was $649(100 \%)$, out of which $130(20.03 \%)$ teeth had pulp stones. The number of teeth with pulp stones was found to be higher in group II than group I.

TABLE 5.

GROUP I: NUMBER OF TEETH WITH PULP STONES IN EACH JAW

\begin{tabular}{|c|c|c|}
\hline Jaw & $\begin{array}{c}\text { Number of teeth with } \\
\text { pulp stones }\end{array}$ & Percentage (\%) \\
\hline Maxilla & 25 & 69.44 \\
\hline Mandible & 11 & 30.55 \\
\hline Total & 36 & 100 \\
\hline
\end{tabular}

In group $I$, the total number of teeth with pulp stones was $36(100 \%)$, out of which $25(69.44 \%)$ teeth were in maxilla and $11 \quad(30.55 \%)$ were in mandible. The number of teeth with pulp stones was found to be higher in maxilla than mandible.

TABLE 6.

GROUP II: NUMBER OF TEETH WITH PULP STONES IN EACH JAW

\begin{tabular}{|c|c|c|}
\hline Jar & $\begin{array}{c}\text { Number of teeth with } \\
\text { pulp stones }\end{array}$ & Percentage (\%) \\
\hline Maxilla & 75 & 57.69 \\
\hline Mandible & 55 & 42.30 \\
\hline Total & 130 & 100 \\
\hline
\end{tabular}


In group II, the total number of teeth with pulp stones was $130(100 \%)$, out of which $75(57.69 \%)$ teeth were in maxilla and $55(42.30 \%)$ were in mandible. The number of teeth with pulp stones was found to be higher in maxilla than mandible.

TABLE 7.

GROUP I: PRESENCE OF PULP STONES IN EACH TYPE OF TEETH:

\begin{tabular}{|c|c|c|c|c|c|c|}
\hline \multirow{2}{*}{ JAW } & \multicolumn{5}{|c|}{ TEETH } & TOTAL \\
\cline { 2 - 6 } & 1st & 2nd & 1st & 2nd & 3rd & \\
Premolar & Premolar & Molar & Molar & Molar & \\
\hline $\begin{array}{c}\text { Number of } \\
\text { teeth with } \\
\text { pulp stones }\end{array}$ & 2 & 3 & 14 & 11 & 6 & 36 \\
\hline $\begin{array}{c}\text { Percentage } \\
(\%)\end{array}$ & 5.55 & 8.33 & 38.88 & 30.55 & 16.66 & 100 \\
\hline
\end{tabular}

In group I, out of $36(100 \%)$ teeth with pulp stones, $2(5.55 \%)$ teeth were $1^{\text {st }}$ premolars, $3(8.33 \%)$ teeth were $2^{\text {nd }}$ premolars, $14(38.88 \%)$ teeth were $1^{\text {st }}$ molars, $11(30.55 \%)$ teeth were $2^{\text {nd }}$ molars and $6(1.66 \%)$ teeth were $3^{\text {rd }}$ molars. It was found that higher number of first molars had pulp stones.

TABLE 8.

GROUP II: PRESENCE OF PULP STONES IN EACH TYPE OF TEETH:

\begin{tabular}{|c|c|c|c|c|c|c|}
\hline \multirow{2}{*}{ JAW } & \multicolumn{5}{|c|}{ TEETH } & TOTAL \\
\cline { 2 - 6 } & 1st & 2nd & 1st & 2nd & 3rd & \\
\hline & Premolar & Premolar & Molar & Molar & Molar & \\
\hline $\begin{array}{c}\text { Number of } \\
\text { teeth with }\end{array}$ & 0 & 0 & 71 & 43 & 16 & \multirow{2}{*}{130} \\
\hline $\begin{array}{c}\text { pulp stones } \\
\text { Percentage }\end{array}$ & 0.00 & 0.00 & 54.61 & 33.07 & 12.30 & 100 \\
\hline
\end{tabular}

In group II, out of $130(100 \%)$ teeth with pulp stones, $71(54.61 \%)$ teeth were $1^{\text {st }}$ molars, $43(33.07 \%)$ teeth were $2^{\text {nd }}$ molars and $16(12.30 \%)$ teeth were $3^{\text {rd }}$ molars. It was found that higher number of first molars had pulp stones.

\section{DISCUSSION:}

Coronary artery disease (CAD) is caused by inadequate blood supply to cardiac muscle due to occlusion of coronary artery. ${ }^{9}$

\section{Calcifying nanoparticles (CNP),} also called nanobacteria, are the first calcium phosphate mineral containing particles isolated from human blood and were detected in numerous pathologic calcification related diseases. $^{5}$

Pulp stones are discrete calcifications within the pulp chamber of teeth. An irritated pulp, when attempts to repair itself, may lead to pulp stone formation. They are usually asymptomatic 


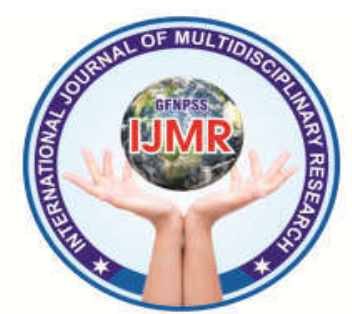

unless they impinge on the nerves or bloodvessels. $^{14}$

Orthopantomograph helps to identify the pulp stones, and allows imaging of a broad anatomic region at a lower radiation exposure. ${ }^{7}$

With this back ground this study was undertaken to evaluate the prevalence of dental pulp stones in coronary artery disease patients and determine the association between dental pulp stones and coronary artery disease using orthopantomograph.

In middle aged population, the burden of CAD is high because of modern lifestyles which include smoking, lack of physical activity and high fat diets leading to obesity, which results in rapid development of atherosclerosis. Other contributing factors include genetic predisposition, increased stress, hypertension and diabetes. ${ }^{2}$

In this study, 32 (64\%) subjects were males and $18(36 \%)$ were females out of $50(100 \%)$ subjects in group I (controls).

In group II (CAD cases), among 50 $(100 \%)$ subjects, $32(64 \%)$ subjects were males and $18(36 \%)$ were females.

We found male preponderance over females in group II (CAD cases).
The reason being, males are more inclined to coronary artery disease as they are stress-prone, because it appears that men coping up with stressful events may be less adaptive physiologically, behaviorally and emotionally contributing to the increased risk and they also indulge themselves more in smoking and alcoholism which contributes to chronic systemic disease. $^{2}$

In group I (controls) out of 50 (100\%) subjects, 14 (28\%) had dental pulp stones.

The finding is in accordance with the study conducted by Sandeep Kumar Bains et $\mathrm{al}^{13}$ and A.C. Edds et al. ${ }^{26}$

The formation of pulp calcification could be due to odontogenic causes like orthodontic forces, attrition, bruxism and systemic causes. ${ }^{10}$

In group II (CAD cases), the total number of teeth with pulp stones was 130 (100\%), out of which $75(57.69 \%)$ teeth were in maxilla and $55(42.30 \%)$ were in mandible.

The number of teeth with pulp stones was found to be higher in maxilla than mandible in group II (CAD cases).

Similar findings were observed in a study conducted by Bains et $\mathrm{al}^{13}$ and Goga et $\mathrm{al}^{12}$. 


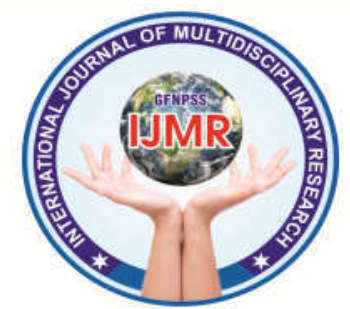

The early eruption of the first indicating an early intervention for molar will expose them for long period of time to the masticatory forces, leading to more degenerative changes, thus causing calcification of the pulp. ${ }^{13}$

Also, the most attributable reason could be that as age advances the structure of the normal pulp varies. This usually leads to a progressive decrease in the number of pulp cells as well as gradual increase in mucopolysaccharides and fibrous elements leading to calcification. ${ }^{13}$

In the present study, we found an increased prevalence of dental pulp stones in patients with coronary artery disease which was statistically significant. Hence there is a possible association of dental pulp stones with coronary artery disease.

It is suggested that, all dental professionals should meticulously evaluate the teeth for pulp stones on orthopantomographs. The presence of dental pulp stones signals for an early referral to the cardiologist.

We recommend orthopantomo graphy as a screening method for identification of dental pulp stones, which can be easily employed on a large-scale basis and applied as a public health measure. The presence of these pulp stones could have a positive correlation with other systemic calcifications as well, diagnosis and management in such disorders.

\section{CONCLUSION:}

Coronary artery disease most commonly occurs due to atherosclerotic occlusion of the coronary arteries and thus curtails life expectancy. Early stage of this disease goes unnoticed, that may lead to hard end points which are associated with significant morbidity and mortality. Although there is tremendous growth in the knowledge of underlying mechanism of heart disease, $30 \%$ of patients do not survive. $^{9}$

Dental radiograph is one of the means of evaluating pulp stones noninvasively.Dental pulp stones can be detected in orthopantomograph, which allows imaging of a broad anatomic region at a lower radiation exposure. ${ }^{7}$

With this back ground this study was undertaken to evaluate the prevalence of dental pulp stones in coronary artery disease patients and determine the association between dental pulp stones and coronary artery disease using orthopantomograph.

In the present study, we found an increased prevalence of dental pulp stones in patients with coronary artery disease 


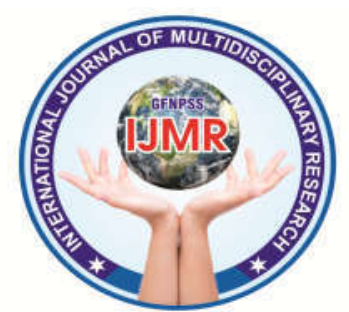

which was statistically significant. Hence there is a possible association of dental pulp stones with coronary artery disease. Routine dental radiographs lend a hand in mapping dental pulp stones. Incidental presence of dental pulp stones on orthopantomographs may point toward hidden potential coronary artery disease. Hence, dental professionals play a pivotal role in detection of dental pulp stones and referral of patients to the cardiologist for appropriate investigations and management of coronary artery disease. Early diagnosis and management of coronary artery disease prevents likely complications, thus reducing morbidity and mortality.

\section{REFERENCES}

1. S K Bhatia. Textbook of biomaterials for clinical applications. 1st ed. New York:Springer Publishers; 2010.

2. Garg M, Aggarwal AD, Kataria SP. Coronary Atherosclerosis and Myocardial Infarction An Autopsy Study. J Indian Acad Forensic Med 2011;33(1).

3. Ajay VS et al. National Cardiovascular Disease Database. With support from Ministry of Health and Family Welfare, Government of India and World Health Organization. Manuscripts developed at the Scientific Secretariat of IC Health,New Delhi.

4. Casper D L et al. Harrison's Principles Of Internal Medicine. 16th ed. McgrawHill Medical Publishing Division; 2005.

5. Aleksova P. Nanobacteria can be the Reason for Creating Sialoliths. IJSR.2015;4(3).

6. Sreelakshmi, Nagaraj $T$, Sinha $T$, Goswami RD, Veerabasaviah BT. A radiographic assessment of the prevalence of idiopathic pulp calcifi cations in permanent teeth: A retrospective radiographic study. J Indian Acad Oral Med Radiol 2014;26(3).

7. Karjodkar FR. Textbook of Dental and Maxillofacial Radiology. 2nd ed. Jaypee Brothers Medical Publishers; 2009.

8. Tortora G J, Derrickson B. Principles of Anatomy and Physiology. 12th ed. John Wiley \& Sons; 2009.

9. Sembulingam K and Sembulingam P. Essentials of Medical Physiology. 6th ed. Jaypee Brothers Medical Publishers; 2012. 10. Nayak M, Kumar J, Prasad KL. A radiographic correlation between systemic disorders and pulp stones. Indian J Dent Res 2010;21(3).

11. Moss-Salentijn L, Klyvert MH. Epithelially induced denticles in the pulps 


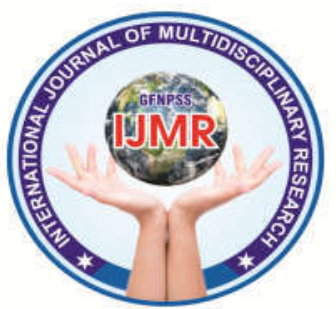

of recently erupted, noncarious human premolars. J Endod 1983;9:554-560.

12. Goga R, Chandler NP, Oginni AO. Pulp stones: a review. Int Endod J 2008;41:457-468.

13. Bains S K, Bhatia A, Singh HP, Biswal SS, Kanth S, Nalla S. Prevalence of Coronal Pulp Stones and Its Relation with Systemic Disorders in Northern Indian Central Punjabi Population 2014:1-5.

14. Vibhute N A, Aniket VH, Rajendra DT, Puja B, Aditi M. Hard Facts about Stones: Pulpal Calcifications: A Review. J Pat Care 2016;2(1).

15. Vataman M, Andrian S, Dragomir R, Salceanu M, Hamburda T. Points of view on pulp mineralization. Oral Health Dent Manag 2004;3.
16. Kretschmer OS, Seybold JW. The bacteriology of dental pulp stones. Dent Cosmos 1936;78.

17. Sundell JR, Stanley HR, White CL. The relationship of coronal pulp stone formation to experimental operative procedures. Oral Surg Oral Med Oral Pathol 1986;25:579-589.

18. Kumar GS. Orban's Oral Histology And Embryology. 12th ed. Elsevier

Publishers; 2008:128-9.

19. Moss-Salentijn L, Hendricks-Klyvert M. Calcified structures in human dental pulps. J Endod 1988;14:184-189.

20. Thomas B, Chandak M, Patidar A, Deosarkar B, Kothari H. Calcified Canals -A Review. IOSR 2014;13(5):38-43. 